\title{
Total phallic reconstruction after penile amputation for donkey bite: Case report and review of the literature
}

\author{
Francesco De Luca ${ }^{1,2}$, Giulio Garaffa ${ }^{3}$, Angela Maurizi ${ }^{1}$, Emy Manzi ${ }^{4}$, \\ Carlo De Dominicis ${ }^{1}$, David Ralph ${ }^{3}$ \\ ${ }^{1}$ Department of Gynaecological and Urological Sciences, Sapienza University of Rome, Rome Italy; \\ ${ }^{2}$ Department of Urology Azienda Ospedaliera San Camillo Forlanini, Rome Italy; \\ ${ }^{3}$ St. Peter's Andrology and the Institute of Urology, University College London Hospitals, London UK; \\ ${ }^{4}$ Department of Surgery P. Stefanini, Sapienza University of Rome, Rome, Italy.
}

\begin{abstract}
Summary There are very few reported cases of traumatic amputation of the male genitalia due to animal bite. The management involves thorough washout of the wounds, debridement, antibiotic prophylaxis, tetanus and rabies immunization followed by immediate reconstruction or primary wound closure with delayed reconstruction, when immediate reconstruction is not feasible. When immediate reconstruction is not feasible, long-term good functional and cosmetic results are still possible in the majority of cases by performing total phallic reconstruction. In particular, it is now possible to fashion a cosmetically acceptable sensate phallus with incorporated neourethra, to allow the patient to void while standing and to ejaculate, and with enough bulk to allow the insertion of a penile prosthesis to guarantee the rigidity necessary to engage in penetrative sexual intercourse.
\end{abstract}

KeY wORDS: Penis; Animal bite; Phalloplasty; Male genital trauma.

Submitted 6 March 2017; Accepted 27 March 2017

\section{Case Report}

A 7-year old boy, living in rural Iran, was bitten through his clothing in the genital area by a donkey. The bite resulted in a partial penile amputation leaving a short penile stump while scrotum and testes were intact (Figure 1). Immediate penile reconstruction was not possible due to the absence of specialist medical facilities.

Since the residual penile stump was inadequate for penetrative sexual intercourse, at age 23 the patient underwent total penile reconstruction with the use of a Radial Artery based Free Flap (RAFF).

Total phallic reconstruction was carried out in 3 stages, each one performed at 6 monthly intervals.

The first stage involved the formation of the phallus, the second stage the sculpture of the neo-glans and the last stage, the insertion of the components of a 3-pieces inflatable penile prosthesis.

Preoperatively an Allen's test was performed in to confirm the patency of the palmar arteries. The flap was formed by two sections separated by a $1 \mathrm{~cm}$ wide de-epithelialized strip. The medial section, which was tubularised to form the neo-urethra was of rectangular shape and meas- ured $4 \times 17 \mathrm{~cm}$. The lateral skin plate, which was $14 \mathrm{~cm}$ long and $13 \mathrm{~cm}$ wide, was wrapped around the neo-urethra in a tube-within-a-tube fashion (3). The vascular supply was the disconnected from the forearm and the phallus was transferred to the recipient pubic region. The penile stump was disassembled with preservation of the crura, the neurovascular bundle and urethra. Inferior epigastric artery, long saphenous vein, deep dorsal vein of the penis, ilioinguinal nerves and deep dorsal nerve of the penis were carefully isolated and prepared for the subsequent microsurgical anastomosis. The arterial anastomosis was performed between the inferior epigastric artery and the radial artery. Venous drainage was guaranteed by the deep dorsal vein of the penis and the long saphenous vein. Orgasmic sensation was guaranteed by the anastomosis between one of the flap nerves to the deep dorsal nerve of the penis while cutaneous sensation was ensured by the ilioinguinal nerve anastomosis. The native urethra stump was spatulated and anastomosed primarily to the phallic neo-urethra. An urethral stent and a suprapubic catheter placed in order to protect the urethral anastomosis whilst healing (4).

The defect on the donor forearm was covered with a fullthickness skin graft (FTSG) harvested from the patient's lower buttock creases (5) (Figure 2).

After 6 months, a neo-glans was sculptured according to the Norfolk technique using a FTSG strip harvested from a relatively hairless area of the abdomen.

Finally, 6 months later, a $18+1 \mathrm{~cm}$ long Titan Touch $^{\circledR}$ inflatable penile prosthesis was inserted into the phallus to guarantee the rigidity necessary to engage in penetrative sexual intercourse. The crura were used to house the rear aspect of the cylinders while a Dacron ${ }^{\circledR}$ tip was fashioned to house the tip of the cylinders thus preventing distal erosion (Figure 3).

After follow-up of 72 months from the last stage of the operation, the patient is fully satisfied with the cosmetic and functional results of surgery. He is able to void while standing and ejaculate from the tip of the phallus. Unfortunately his penile implant got infected 3 times, which required explantation and led to phallus shortening. As a consequence, at present, his penile implant is $16 \mathrm{~cm}$ long. 
Figure 1.

Penile amputation.

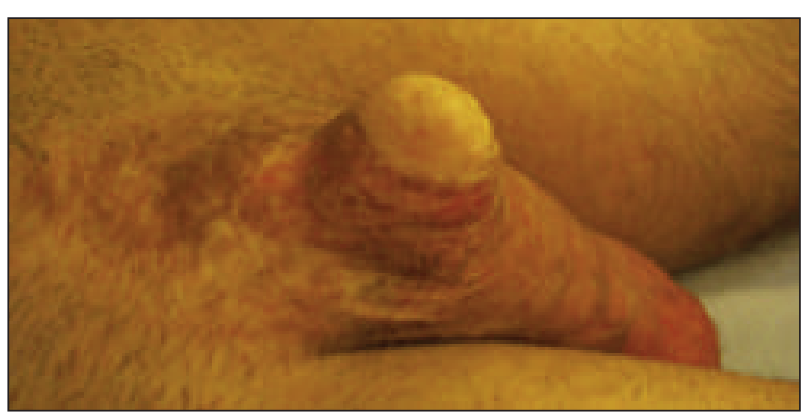

\section{Discussion}

To date, including the present case, there are 57 published cases of animal bites to male genitalia.

A search was conducted using the following words: "trauma", "male genitalia", "penis", "testis" and "animal bite" from December 1966 to December 2016.

The majority of cases are due to dog 34 (66.6\%), followed by snake $4(7.8 \%)$, viper 2 (3.9\%), horse 2 (3.9\%), monkey 2 (3.9\%), donkey 2 (3.9\%), mule (1.9\%), alligator $1(1.9 \%)$, rat 1 ( $1.9 \%)$, pig 1 (1.9\%), parrot fish 1 (1.9\%) (Table 1 and 2).

Animal bites cause penetrating genital trauma, and might increase the risk of infection. Genital bites are much
Figure 2.

Donor site forearm.

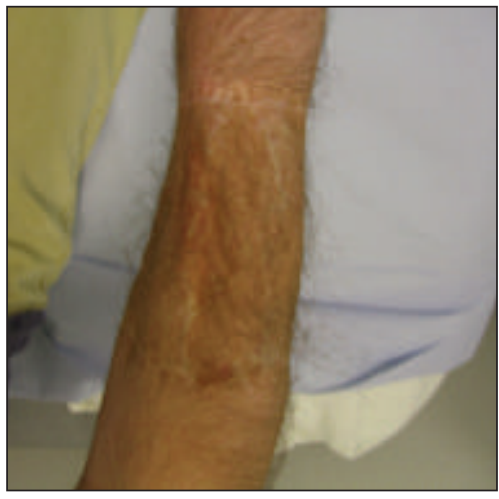

Figure 3.

Phalloplasty with penile prosthesis.

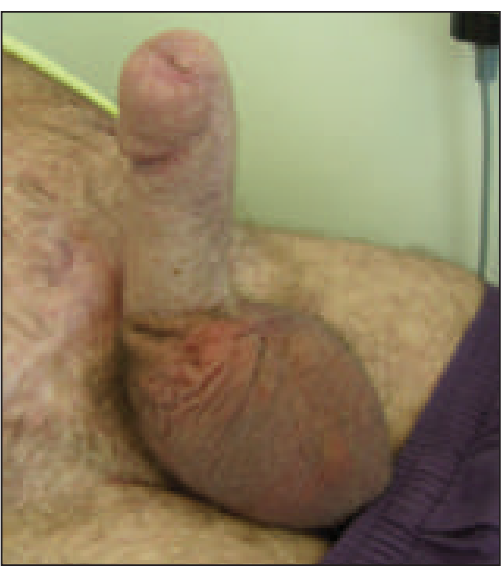

\begin{tabular}{|lll|}
\hline Animal & $\mathbf{N}$ & $\%$ \\
\hline dog & 34 & 66,6 \\
\hline snake & 4 & 7,8 \\
\hline viper & 2 & 3,9 \\
\hline horse & 2 & 3,9 \\
\hline monkey & 2 & 3,9 \\
\hline donkey & 2 & 3,9 \\
\hline mule & 1 & 1,9 \\
\hline alligator & 1 & 1,9 \\
\hline rat & 1 & 1,9 \\
\hline pig & 1 & 1,9 \\
\hline parrot fish & 1 & 1,9 \\
\hline
\end{tabular}

Table 1.

Cases reported in literature.

\begin{tabular}{|c|c|c|c|c|}
\hline Animal & $\mathbf{N}$ & Author & Injury & Man/child \\
\hline dog & 1 & Aineskog H. et al. 2016 & penile skin avulsion & adult \\
\hline parrot fish & 1 & Kobayashi SA, et al. 2015 & avulsion of penile foreskin & adult \\
\hline snake & 1 & Tamou Sambo B, et al. 2015 & penoscrotal gangrene & adult \\
\hline viper & 1 & Koffi NR, et al. 2015 & swelling & child \\
\hline viper & 1 & Hussain T, et al. 2015 & swelling and hemorrhagic bullae & adult \\
\hline $\operatorname{dog}$ & 1 & Miodrag A, et al. 2014 & penile skin avulsion & adult \\
\hline mule & 1 & Lakmichi MA, et al. 2011 & complete penile avulsion & adult \\
\hline rat & 1 & Haldar P, et al. 2011 & transection of the urethra & child \\
\hline snake & 1 & Kossoko H, et al. 2011 & urethra injury & adult \\
\hline $\operatorname{dog}$ & 3 & Bothra R, et al. 2011 & emasculation, 2 lacerated wound & child \\
\hline dog & 1 & Frank M, et al. 2010 & genital avulsion & adult \\
\hline dog & 1 & Saleh D, et al. 2009 & lest testicular rupture & adult \\
\hline$\overline{\operatorname{dog}}$ & 1 & Bertozzi M, et al. 2009 & damage of the right vas deferens & child \\
\hline $\operatorname{dog}$ & 1 & Hon KL, et al. 2007 & swelling & child \\
\hline snake & 1 & Babata AL, et al. 2006 & scrotum gangrene & adult \\
\hline dog & 1 & Leung AK, et al. 2005 & skin avulsion & child \\
\hline $\operatorname{dog}$ & 1 & Ku JH, et al. 2005 & amputation penis and testes & child \\
\hline$\overline{d o g}$ & 1 & Budhiraja S, et al. 2002 & loss of right testis & child \\
\hline Pig & 1 & Georgiou P, et al. 2001 & subtotal avulsion of penile skin & adult \\
\hline dog & 8 & Gomes CM, et al. 2000 & 5 skin loss,2 spermatic cord avulsion, & 8 children \\
\hline horse & 1 & Gomes CM ,et al. 2000 & 1 partial penis avulsion & adult \\
\hline donkey & 1 & Gomes CM, et al. 2000 & 1 complete scrotal avulsion & adult \\
\hline $\operatorname{dog}$ & 7 & Cummings JM, et al. 2000 & skin avulsion & adults 3 children \\
\hline monkey & 2 & Singla SL, et al. 1997 & & \\
\hline$\overline{\operatorname{dog}}$ & 1 & Redman J. F., 1995 & complete testes avulsion & child \\
\hline alligator & 1 & Katlowitz NM, et al. 1995 & testes avulsion & \\
\hline $\operatorname{dog}$ & 2 & Tuggle DW et al. 1993 & external genitalia loss & children \\
\hline $\operatorname{dog}$ & 1 & Wolf et al. 1993 & both testes loss & child \\
\hline $\operatorname{dog}$ & 1 & Piza-Katzer H, et al. 1989 & skin damage & adult \\
\hline dog & 2 & Donovan JF et al. 1989 & penile and scrotal skin avulsion & children \\
\hline \multicolumn{5}{|l|}{ non specified } \\
\hline snake & 1 & Sinha SN, et al. 1975 & scrotal skin necrosis & \\
\hline horse & 1 & Noto L 1966 & elephantiasis & \\
\hline
\end{tabular}

Table 2.

Cases reported in literature. more common in children (60\%) than adults (40\%). Morbidity is directly related to the severity of the injury and to the time elapsed before seeking for medical assistance.

Treatment includes thorough washing and irrigation with normal saline solution, debridement and broad- 
spectrum antibiotics prophylaxis, as the main risk is infection. Primary closure is often recommended in most cases delaying reconstructive surgery to a later date.

When the victim is a child, or the wound has been caused by an animal, infectious complications are usually minor, as medical treatment is sought reasonably quickly. Pasterurella multocida is often present (20-50\% of dog bites). Cellulitis often results in premature sepsis (within 24 hours).

Antibiotic treatment should be broad-spectrum beta-lactam with beta-lactamase inhibitors. Fluoroquinolones, cotrimoxazole or chloramphenicol are valid alternatives. The duration of treatment should be individualised and last at least 10-14 days.

Rabies vaccination will depend on local sanitary policy. Appropriate tetanus vaccination is required.

\section{REFEREnCes}

1. Lakmichi MA, Wakrim B, Jarir R, et al. Mule bite to male genitaliawith complete penile and anterior urethra amputation: unsual case and review of the literature. ISRN Urol. 2011; 2011:723154.

2. Evgeniou E, Markeson D, Iyer S, et al. The management of animal bites in the United Kingdom. Eplasty. 2013; 13:e27. Print 2013.

3. Garaffa G, Raheem AA, Christopher NA, et al. Total phallic reconstruction after penile amputation for carcinoma. BJU Int. 2009; 104:852-6.

4. Massanyi EZ, Gupta A, Goel S, et al. Radial forearm free flap phalloplasty for penile inadequacy in patients with extrophy. J Urol. 2013; 190 (4 Suppl):1577-82.

5. Doornaert M, Hoebeke P, Ceulemans P, et al. Penile reconstruction with the radial forearm flap: an update. Handchir Mikrochir Plast Chir. 2011; 43:208-14.

\section{Correspondence}

Francesco De Luca, MD (Corresponding Author)

francescodelucal0@gmail.com

Angela Maurizi, MD

angmau81@hotmail.com

Carlo De Dominicis, MD

carlo.dedominicis@uniromal.it

Viale dell'Università, 31/33, 00161 Roma, Italy

Giulio Garaffa, MD

giuliogaraffa@gmail.com

David Ralph, MD

dralph@andrology.co.uk

145 Harley Street London W1G 6BJ (UK)

Emy Manzi, MD

emymanzi@gmail.com

Viale del Policlinico 155, 00161 - Roma, Italy 